\title{
Reticulocyte release factor
}

\author{
HILLAS SMITH \\ From the Institute of Clinical Research, Middlesex Hospital Medical School, London
}

SYNOPSIS Some investigators have had conspicuous success with reticulocyte counting methods in animals as assay techniques for plasma erythropoietic hormone, but there has been some diversity in the reticulocytosis obtained by different workers.

This communication reports the disparity between the marrow erythroid activity (assessed by $\overrightarrow{\mathrm{c}}$ counting colchicine-blocked mitoses) and the reticulocyte response in normal Wistar rats injected $\dot{\omega}$ with plasma extracts. In bled rats in which mitotic activity was of comparable range to the extract- $\tilde{O}$ injected rats a considerable reticulocytosis resulted. Evidence is presented that the most likely explanation for the lack of reticulocytosis in the injected group is the absence of a factor necessary for the release of reticulocytes.

It is emphasized that in assay methods using reticulocyte counts, weight, age, and strain of the animals may be of critical importance.

In recent years interest in reticulocytes has revived. In 1926 the introduction of liver therapy for pernicious anaemia focused attention on the reticulocyte response following treatment, and this has been well studied and fully documented (e.g., Minot, Murphy, and Stetson, 1928). The present interest in reticulocytes has been sharpened by the widespread use of reticulocyte counts in the study of the basic stimulus to erythropoiesis and especially the reticulocyte response which may follow the injection into animals of plasma and plasma extracts.

This communication results from the study of the behaviour of bone marrow and the reticulocytes in the peripheral blood after the injection of stimulating material into normal rats.

The factors influencing the number of reticulocytes in the peripheral blood are:-

RATE OF PRODUCTION OF RETICULOCYTES Assuming a healthy marrow, very many stimuli may result in reticulocytosis. These are haemorrhage; treatment with specific haematinics, e.g., vitamin $B_{12}$ in pernicious anaemia or iron in iron-deficiency anaemia; tissue anoxia caused by high altitudes, right-to-left cardiac shunts, or defects in pulmonary diffusion; cobalt; various, such as the effects of thyroid extract or corticotrophin. The response to these stimuli is not immediate, that is, it may take hours or days to develop, and it is inferred that these stimuli act not by the immediate release of existing Received for publication 20 June 1961. reticulocytes but by causing increased cell production. This concept takes no account of the number of reticulocytes in the bone marrow and the proportion of them released into the peripheral blood nor of the mechanisms responsible for that release.

DEPOT DEPLETION A variable, and usually transient, reticulocytosis has been found to follow injection of adrenaline, intra-arterial sodium carbonate, and various procedures on the central nervous system, such as air encephalography (Istamanowa and Chudoroschewa, 1930). This type of response occurs in from 15 minutes to several hours and can only be explained by the release of cells from depots.

RATE OF DISAPPEARANCE OF RETICULOCYTES The $\frac{7}{2}$ life span of reticulocytes depends on factors influencing their destruction and maturation. Reticulo- o cytes possibly react in the same way as mature red cells to chemical and antigenic destructive factors. O They differ little from mature erythrocytes in their $\omega$ osmotic fragility (Whitby and Hynes, 1935). The rate of maturation of reticulocytes appears to be under the control of a reticulocyte-ripening substance demonstrated by Plum (1949).

\section{PRESENT STUDY}

METHODS Active plasma was obtained by bleeding $\sigma$ normal rabbits $(2.0$ to $3.5 \mathrm{~kg}$.) $10 \mathrm{ml} . / \mathrm{kg}$. body weight for 
three consecutive days to a haemoglobin level of approximately $40 \%(5.9 \mathrm{~g}$.). On the fourth day the animals were exsanguinated by aortic catheter under nembutal anaesthesia. The blood was received into bottles using heparin as anticoagulant and the plasma separated by centrifugation at $-3^{\circ} \mathrm{C}$. An average animal gave $80 \mathrm{ml}$. of blood with approximately $50 \mathrm{ml}$. of plasma from which a $20 \mathrm{ml}$. extract was prepared.

Extracts of plasma were prepared by the method of Borsook, Graybiel, Keighley, and Windsor (1954) as modified by Lowy, Keighley, Borsook, and Graybiel (1959).

The test animals were 150 to $180 \mathrm{~g}$. Wistar rats from a closed colony.

Plasma or plasma extract was injected subcutaneously for three consecutive days; 18 hours after the third injection blood was taken from the tail vein for reticulocyte counts. An equal volume of blood was added to brilliant cresyl blue stain and the tubes incubated at $37^{\circ} \mathrm{C}$. for five minutes. After careful shaking wet smears were prepared. One thousand red cells were counted and the number of reticulocytes was expressed as a percentage.

To determine the mitotic index, $0.05 \mathrm{mg}$. colchicine (pure alkaloid in saline)/100 g. was injected subcutaneously immediately after blood had been taken for reticulocyte counts. Five hours after the colchicine injection the rats were sacrificed and duplicate smears were made from femoral marrow and stained with May GrunwaldGiemsa stain. Five hundred red cell precursors were counted, the number of mitoses noted, and the result, the mitotic index, expressed as a percentage (Smith, 1961). The normal mitotic index for eight unstimulated rats given colchicine was found to be $3 \cdot 8 \pm 1 \cdot 4$ (S.E.M.).

\section{RESULTS}

Using the plasma extracts as described, a constant and reproducible reticulocyte response could not be produced. A survey of the literature showed that other workers had found $(a)$ no reticulocyte response whatsoever (Kinard, Griffin, and Kinard, 1960); (b) variable results (Gordon and Dubin, 1934); and (c) a consistent response (Erslev, 1953; Borsook et al., 1954). Despite the difference in size of dose and in species of animals used by various workers, the lack of consistent response in the literature is striking. Some of this inconsistency might arise if some fractions selectively stimulated certain parameters.

An examination of the bone marrow of a group of rats injected with active extract but showing no reticulocytosis suggested an increase in erythroid elements. This marrow response has been quantitated using colchicine to prevent mitosis developing beyond the metaphase.

Fig. 1 shows the reticulocyte response and the mitotic indices compared in the same animals stimulated with active extract in doses varying from $0.02 \mathrm{ml}$. to $4.0 \mathrm{ml}$. It is clear that the reticulocyte results do not follow a dose response relation,
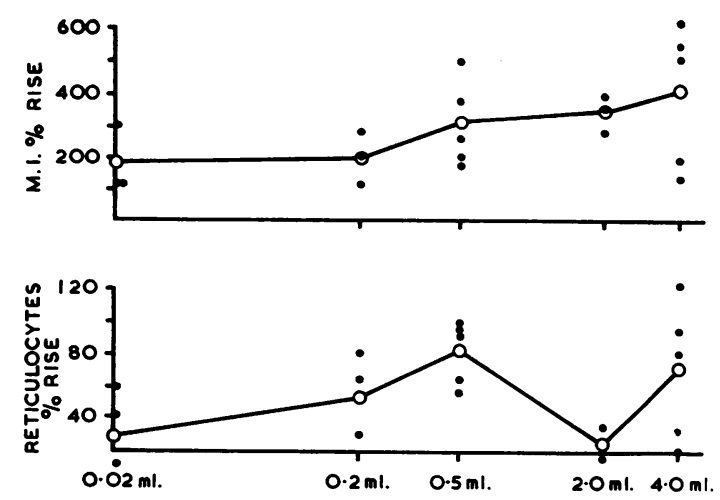

FIG. 1. Comparison of reticulocytosis and mitotic index in five groups of rats. Note good dose response relation in mitotic index, but no correlation with dose in reticulocyte values.

whereas the mitotic indices do, but the wide scatter of values does not permit dose differentiation. A significant feature is the marked increase in the mitotic index for doses as small as $0.02 \mathrm{ml}$.

An attempt was then made to stimulate the marrow in rats by haemorrhage comparable to the stimulation produced by injection. Two groups of rats were respectively bled $1.0 \mathrm{ml} . / 100 \mathrm{~g}$. body weight for three consecutive days and $0.5 \mathrm{ml} . / 100 \mathrm{~g}$. for two days. On the fourth day blood and marrow preparations were made to evaluate the reticulocytes and the mitotic index (Table I).

\section{TABLE I}

RAT RETICULOCYTOSIS AND MITOTIC INDICES IN TWO GROUPS OF BLED RATS

\begin{tabular}{|c|c|c|c|c|}
\hline & Reticulocytes & Mean (\%) & Mitotic Index & Mean ( \\
\hline \multicolumn{5}{|c|}{ Bled $(1 \mathrm{ml} . / 100 \mathrm{~g}$.$) for three days$} \\
\hline 1 & $10 \cdot 0$ & \multirow{3}{*}{$9 \cdot 9$} & 11.6 & \multirow{3}{*}{$15 \cdot 6$} \\
\hline 2 & $11 \cdot 6$ & & $16 \cdot 0$ & \\
\hline 3 & $8 \cdot 3$ & & $19 \cdot 8$ & \\
\hline \multicolumn{5}{|c|}{ Bled $(0.5 \mathrm{ml} . / 100 \mathrm{~g}$.) for two days } \\
\hline 1 & $8 \cdot 6$ & & 14.0 & \multirow{4}{*}{$12 \cdot 2$} \\
\hline 2 & 6.7 & $8 \cdot 5$ & $13 \cdot 0$ & \\
\hline 3 & 6.7 & & $10 \cdot 3$ & \\
\hline 4 & $12 \cdot 0$ & & 11.6 & \\
\hline
\end{tabular}

In Fig. 2 the response of both the mitotic index and the reticulocytes has been plotted, together with the response in the injected animals. It is seen that for a comparable range of marrow erythroid activity there is a marked difference in the reticulocyte levels, absolute separation occurring except for one value.

The presence of a very high degree of erythroid mitotic activity in both groups with a high reticulocytosis in the bled animals only suggests the absence of a factor responsible for the release of reticulocytes 
FIG. 2. For a comparable range of marrow mitotic activity the reticulocytosis in bled rats (solid dots) and rats injected with active plasma extracts (open circles) form two separate populations.

in the injected group, and it is convenient (though not necessarily correct) to consider that one factor stimulated the erythron and another allowed the reticulocytes to be liberated into the peripheral blood. Assuming the presence of two factors and noting the high level of mitosis and reticulocytosis in bled animals, both factors might be expected to be present in whole plasma from bled animals and the injection of whole plasma might be expected to produce a rise in both parameters.

Table II shows the reticulocyte and marrow response in five rats injected for three days with $0.5 \mathrm{ml}$. whole plasma from bled rabbits. A modest, but significant, rise in reticulocytes occurred with a proportionate rise in the mitotic index. Table II also shows that extract prepared in the usual way and then boiled for 15 minutes caused no increase in reticulocyte values whereas the mitotic index remained high.

\section{TABLE II}

RETICULOCYTE AND MARROW RESPONSE IN RATS AFTER INJECTION OF WHOLE PLASMA OR PLASMA EXTRACT

\begin{tabular}{llccc} 
Injection & $\begin{array}{l}\text { Mean } \\
\text { Reticulocytes } \\
(\%) \\
\pm S . E . M .\end{array}$ & $\begin{array}{l}\text { Mitotic } \\
\text { Index } \\
\pm \text { S.E.M. }\end{array}$ & $\begin{array}{l}\text { No. of } \\
\text { Animals }\end{array}$ \\
\hline $\begin{array}{l}0.5 \mathrm{ml} \text { extract from } \\
\text { unbled rabbits }\end{array}$ & $3.5 \pm 1.0$ & $6.4 \quad \pm 1.0$ & 5 \\
$\begin{array}{l}\mathbf{0} 5 \mathrm{ml} \text {. whole plasma } \\
\text { from bled rabbits }\end{array}$ & $6.4 \quad \pm 0.001$ & $11.2 \quad \pm 0.3$ & 5 \\
$\begin{array}{l}0.5 \mathrm{ml} \text {. extract boiled } \\
15 \mathrm{~min} .\end{array}$ & $3.5 \pm 0.3$ & $11.7 \pm 1.7$ & 3
\end{tabular}

It might be argued that in rats stressed by repeated haemorrhage increased corticotrophin activity might be responsible for the liberation of reticulocytes. Table III shows the result of injecting $2 \cdot 5$ i.u. soluble A.C.T.H. subcutaneously 17 hours before taking specimens, the rats having had three daily injections
TABLE III

RETICULOCYTE AND MARROW RESPONSE

AFTER INJECTION OF A.C.T.H.

\begin{tabular}{|c|c|c|c|}
\hline Injection & $\begin{array}{l}\text { Mean } \\
\text { Reticulocytes } \\
(\%) \\
\pm \text { S.E.M. }\end{array}$ & $\begin{array}{l}\text { Mitotic } \\
\text { Index } \\
\pm \text { S.E.M. }\end{array}$ & $\begin{array}{l}\text { No. of } \\
\text { Animals }\end{array}$ \\
\hline
\end{tabular}

$0.5 \mathrm{ml}$. extract from

bled rabbits

$5.7 \quad \pm 0.03 \quad 16 \cdot 2 \quad \pm 7 \cdot 0 \quad 5$

$0.5 \mathrm{ml}$. extract +2.5 i.u.

A.C.T.H.

$4.4 \pm 1 \cdot 1 \quad 12 \cdot 6 \quad \pm 1 \cdot 8 \quad 3$

of $0.5 \mathrm{ml}$. plasma extract. There is no significant rise in the reticulocyte level, and the mitotic index ? remains at the expected high level.

\section{DISCUSSION}

A disparity in reticulocyte response was demonstrated in rats when erythroid marrow activity of comparable range resulted from two different types of stimuli. The lack of response in the injected group might result from three factors.

FAILURE TO PRODUCE RETICULOCYTES This seems very unlikely in view of the high level of mitotic activity unless there is a very marked wastage of cells, possibly due to the production of large numbers of abnormal forms. Linman, Korst, and Bethell (1959) have described the production of short-lived microcytes by one plasma fraction and it is just possible that the reticulocyte precursors of these microcytes also have a reduced life span. But this is a theoretical assumption without supporting evidence.

INCREASED MATURATION RATE OF RETICULOCYTES Rapid maturation could certainly account for some loss of cells if a high level of reticulocyte ripening substance is present in the injected group. This factor is more likely to be operative in the bled group, as a high level of this substance has been shown to be present after haemorrhage (Plum, 1949).

FAILURE OF MARROW TO RELEASE RETICULOCYTES This is the most likely explanation and it is difficult to escape the corollary that the stimuli for cellular division and for the release of reticulocytes are not identical.

A single injection of A.C.T.H. failed to produce a reticulocytosis despite evidence of erythroid hyperactivity. It is possible that A.C.T.H. given for a longer period might cause a reticulocytosis and this is favoured by the finding of increased reticulocyte values in patients on long-term A.C.T.H. therapy (Thorn, Forsham, Frawley, Hill, Roche, 
Staehelin, and Wilson, 1950). This suggests that A.C.T.H. acts by causing increased marrow activity rather than by releasing reticulocytes.

A significant increase in reticulocyte values occurred after the injection of active whole plasma (Table III), while extracts of this plasma either boiled for 15 minutes or brought to $75^{\circ} \mathrm{C}$. for two minutes failed to cause increased reticulocyte values, although the mitotic indices were increased in the latter two groups.

These data suggest that heat selectively destroys a factor, which is not A.C.T.H., responsible for reticulocyte release. Linman, Korst, and Bethell have often pointed out that two erythropoietic factors operate, one, a heat-stable, ether-soluble factor, responsible for cellular division, and a heat-labile, ether-insoluble factor, which governs haemoglobin synthesis.

From the data presented here it seems probable that the mitotic index assays the factor responsible for cellular division and that one might expect high reticulocyte counts in extract-stimulated animals as Linman, Korst, and Bethell have shown. The failure to demonstrate this response in the present series could indicate differences in method or selection of animals, such as weight of animals used, or minor differences in extraction procedure: alternatively, the potency of the material used in the present series may be low, although it does have a marked effect on erythroid mitotic activity. However, the failure to produce high reticulocyte values in the presence of marked erythroid hyperactivity still requires an explanation; the absence of a heat-labile agent, which is not A.C.T.H. and is responsible for the release of reticulocytes, seems the most likely explanation.

Stohlman (1959) found that rats which had been bled but at the same time exposed to $50 \% \mathrm{O}_{2}$ had a reduced capacity to promote $\mathrm{Fe} 59$ incorporation but that reticulocyte values were not abolished. This interesting finding suggests that reticulocytosis and the ability to produce increased $\mathrm{Fe} 59$ incorporation are not necessarily controlled by identical factors. The studies of Altland and Parker (1955) show that in the box turtle reticulocytosis could be induced by haemorrhage, but not when the turtles were exposed to barometric pressures equivalent to a simulated altitude of 35,000 to 45,000 feet.
Seip (1953) described an experiment in which 15 to $30 \mathrm{ml}$. doses of plasma from cases of erythroblastosis foetalis were injected into normal individuals. A marked rise in the reticulocyte count occurred 30 minutes after the injections. This plasma taken from patients with very high reticulocyte counts should contain increased quantities of release factor and the time relations make this more than conjecture.

\section{CONCLUSION}

The literature shows that there is a diversity of results with regard to reticulocyte levels following the injection into animals of active plasma extracts.

Under the conditions described here, rats which had been bled showed a marked reticulocytosis whereas rats injected with active plasma extract did not have raised reticulocyte values. Both groups had a comparable range of increased marrow erythroid activity. This evidence suggests that a heat-labile factor, which is not A.C.T.H., is responsible for the release of reticulocytes.

I wish to acknowledge the help and advice of Dr. G. D. Hadley who sponsored the work. I am also indebted to Professor A. Kekwick and the members of the Clinical Research Committee for research facilities at the Institute. The work was carried out during the tenure of a Leverhulme research scholarship.

\section{REFERENCES}

Altland, P. D., and Parker, M. (1955). Amer. J. Physiol., 180, 421. Borsook, H., Graybiel, A., Keighley, G., and Windsor, E. (1954). Blood, 9, 734.

Erslev, A. (1953). Ibid., 8, 349.

Gordon, A. S., and Dubin, M. (1934). Amer. J. Physiol., 107, 704.

Istamanowa, T., and Chudoroschewa (1930). Z. ges. exp. Med., 71, 212.

Kinard, F. W., Griffin, F. F. Jr., and Kinard, F. W. Jr. (1960). Nature (Lond.), 186, 561.

Linman, J. W., Korst, D. R., and Bethell, F. H. (1959). Ann. N.Y. Acad. Sci., 77, 638

Lowy, P. H., Keighley, G., Borsook, H., and Graybiel, A. (1959). Blood, 14, 262

Minot, G. R., Murphy, W. P., and Stetson, R. P. (1928). Amer. J. med. Sci., 175, 581 .

Plum, C. M. (1949). Acta haemat. (Basel), 2, 317.

Seip, M. (1953). Acta med. scand., Suppl. 282

Smith, Hillas (1961). Nature (Lond.), 190, 640.

Stohlman, F. Jr. (1959). Ann. N.Y. Acad. Sci., 77, 710.

Thorn, G. W., Forsham, P. H., Frawley, T. F., Hill, S. R. Jr., Roche, M., Staehelin, D., and Wilson, D. L. (1950). New Engl. J. Med., 242, 783.

Whitby, L. E. H., and Hynes, M. (1935). J. Path. Bact., 40, 219. 